\title{
Laparoscopic repair of giant hiatal hernia for elderly patients
}

\author{
Lei Guan, Yusheng Nie, Xin Yuan, Jie Chen, Huiqi Yang \\ Department of Hernia and Abdominal Wall Surgery, Beijing Chaoyang Hospital, Capital Medical University, Beijing, China \\ Contributions: (I) Conception and design: H Yang; (II) Administrative support: J Chen; (III) Provision of study materials or patients: H Yang; (IV) \\ Collection and assembly of data: L Guan, X Yuan; (V) Data analysis and interpretation: L Guan, Y Nie; (VI) Manuscript writing: All authors; (VII) \\ Final approval of manuscript: All authors. \\ Correspondence to: Huiqi Yang, MD. Department of Hernia and Abdominal Wall Surgery, Capital Medical University, Jingyuan Road No. 5, \\ Shijingshan District, Beijing 100043, China. Email: yang.huiqi@qq.com.
}

Background: Giant hiatal hernias are more common in older patients and can significantly reduce their quality of life. However, open surgery for patients of advanced age is thought to be associated with high morbidity and mortality. The aim of this retrospective study was to evaluate the safety of laparoscopic giant hiatal hernia repair for elderly patients as compared to younger patients.

Methods: From January 2015 to January 2020, 152 consecutive patients underwent laparoscopic mesh repair of giant hiatal hernia. Two cases of missing follow up were excluded. Patients were divided into an elderly group $(\mathrm{N}=62$, age $\geq 75)$ and a younger group $(\mathrm{N}=88$, age $<75)$. Interrupted non-absorbable suture was applied for crus closure and as an additional reinforcement, the mesh was fixed with absorbable tacks or medical glue. Procedure-related complications, score-based variation tendency of symptoms, gastrointestinal quality of life index (GIQLI), mortality, recurrence rate, hemoglobin, and the use of PPI were investigated.

Results: All patients underwent the procedure uneventfully. Dor fundoplication was used in 39 patients $(62.9 \%)$ in the elderly group and $44(50.0 \%)$ in the younger group and no case was converted to open. While the elderly group had a significantly higher percentage of ASA Class level 3 and cardiovascular and cerebrovascular diseases as compared to the younger group, the two groups had similar operative times, intraoperative blood loss, and percentage of intrathoracic stomach. Elderly group patients tended to have higher perioperative complications including pneumonia (3.2\%) and atelectasis (3.2\%) without statistical significance, as well as transfer to the intensive care unit compared, to younger patients (9.7\% vs. $3.2 \%$; $\mathrm{P}=0.144)$. The mean post-operative hospital stay was also significantly shorter in the younger group (2.8 days) compared with the elderly group (3.5 days; $\mathrm{P}=0.001$ ). There was no mortality, recurrence, meshrelated complications such as visceral erosion, adhesion, or severe dysphagia during follow up in the two groups, and both groups demonstrated significant improvement in GIQLI scores and hemoglobin. The percentage of patients who needed PPI was also reduced in both groups.

Conclusions: Laparoscopic mesh repair of giant hiatal hernia for elderly patients is safe and effective when performed at experienced centers.

Keywords: Hiatal hernia (HH); laparoscopy; giant; elderly; fundoplication

Submitted Mar 05, 2021. Accepted for publication Apr 22, 2021.

doi: 10.21037/atm-21-1495

View this article at: http://dx.doi.org/10.21037/atm-21-1495

\section{Introduction}

Hiatal hernia $(\mathrm{HH})$ is a common disorder with a large proportion of asymptomatic and symptomatic patients well treated medically (1). In contrast, giant hiatal hernia is usually associated with severe acid regurgitation, heartburn, or other reflux symptoms (2) and it is defined as hernia with more than $30 \%$ of the stomach translocating into the thoracic cavity (3). A previous study indicated laparoscopic $\mathrm{HH}$ repair was associated with lower mortality and shorter 

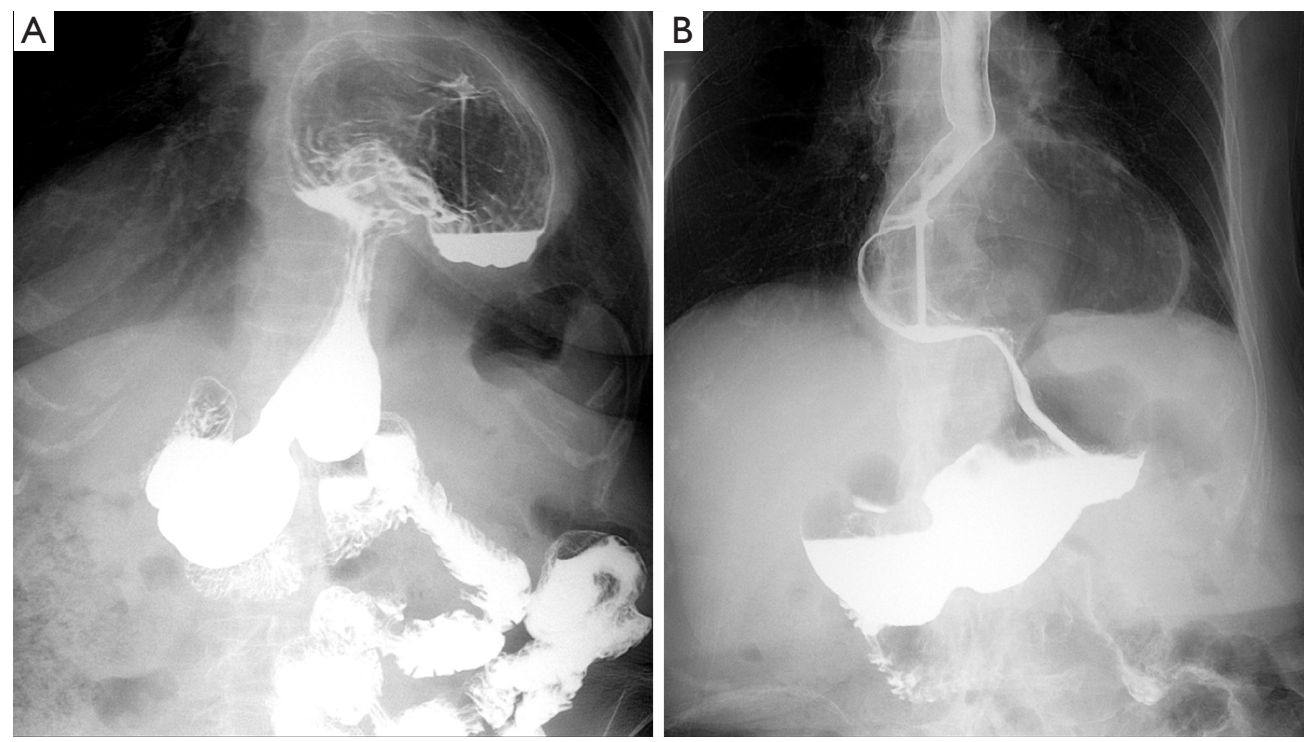

Figure 1 Two patient's giant hiatal hernia with most of the stomach herniated into the chest.

hospital stay compared to open surgery (4) and laparoscopic giant hiatal hernia mesh repair has been demonstrated as an effective and safe procedure with significant improvement of outcomes and low recurrence rate (5-8). Compare to open surgery, laparoscopic giant hiatal hernia repair provides better operating view, therefore facilitating the hiatus repair and fundoplication. However, the number of patients over 65 years is gradually increasing worldwide (9) and elderly patients with giant hiatal hernia suffer higher surgical complication rates than young patients $(10,11)$. Therefore, a cautious approach has been adopted to performing this operation on elderly patients, especially for those with concomitant medical problems. While some studies have recently reported favorable outcomes for patients of advanced age (12-16), the present study compared the safety and the efficiency of this procedure between young and elderly patients in our center.

We present the following article in accordance with the STROBE reporting checklist (available at http://dx.doi. org/10.21037/atm-21-1495).

\section{Methods}

Details of consecutive patients undergoing elective laparoscopic mesh repair of giant hiatal hernia (defined as $\geq 30 \%$ of the stomach herniated into the thoracic cavity) in the Department of Hernia and Abdominal Wall Surgery, Beijing Chaoyang Hospital between January 2015 and
January 2020 were recorded retrospectively (Figure 1). The diagnosis was based on gastroscopy, CT scan, and barium meal contrast esophageal radiography. The surgery was performed laparoscopically. For the elderly patients with medical history of cardiopulmonary disease, the lower pressure of pneumoperitoneum is usually applied to prevent from the possible cardiopulmonary complications and neck emphysema. All surgeries were performed by one experienced surgeon who followed the principles of complete reduction of the hernial sac, stomach, and associated herniated structures with extensive dissection to ensure adequate esophageal mobility (17). The anterior and posterior crus were closed with non-absorbable sutures (Prolene) intermittently, and a piece of titanized polypropylene posterior mesh (PFM Germany) was fixed on the diaphragm with absorbable tacks and medical glue (Compont Medical Adhesive, $1.5 \mathrm{~mL} /$ tube; Beijing Compont Medical Devices Co., Ltd., Beijing, China) (Figure 2). The subsequent fundoplication was performed according to preoperative $24 \mathrm{~h}$ esophageal $\mathrm{PH}$ monitoring and manometry outcome and patients were given prophylactic heparin according to their weight after operation. Follow-up data were collected from the outpatient clinic, questionnaire and telephone interview at $6 \mathrm{~ms}$ after surgery. The analyzed data included procedurerelated complications, score-based variation tendency of symptoms, (the lightest score was 0 and the worst score was 10), GIQLI (range from 0 to 144 scores), mortality, 


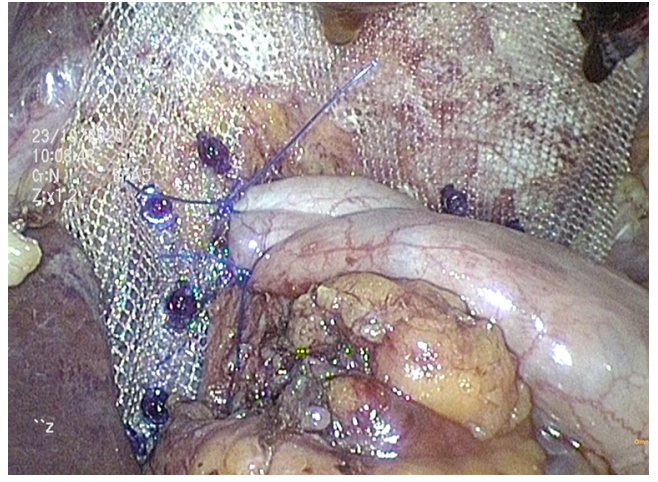

Figure 2 The mesh was fixed on the diaphragm with absorbable tacks and Dor fundoplication was performed.

recurrence rate, hemoglobin, and use of PPI. The patients missing follow up were excluded from study.

\section{Statistical analysis}

Statistical analysis was performed using SPSS Statistics 21 software (IBM, New York, United States). Chi square test or Fisher's exact test was used for categorical variables and two-sample $t$ test or Wilcoxon's test for continuous variables. All statistical tests were two-sided and $\mathrm{P}$ values of 0.05 or less were considered significant.

\section{Ethical statement}

All procedures performed in this study involving human participants were in accordance with the Declaration of Helsinki (as revised in 2013). The study was approved by institutional ethics committee Beijing Chaoyang Hospital (No.: 2020-2-2035). Individual consent for this retrospective analysis was waived.

\section{Results}

\section{The outcome of preoperative evaluation (Table 1)}

From January 2015 to January 2020, a total of 152 elective patients (69 males and 83 females) were admitted to our center, including 64 patients (aged $\geq 75$ ) with an average age of 80.1 and 88 patients (aged $<75$ ) with an average age of 57.7. Two patients in group of more than 75 missing follow up were excluded. Cardiovascular and cerebrovascular disease, including hypertension, diabetes, coronary heart disease, and cerebral infarction, were seen in $64.5 \%$ of the elderly group compared with $35.2 \%$ in the younger group $(\mathrm{P}=0.001)$ and the percentage of ASA Class level 3 in the elderly group (17.7) was more than the younger group (6.8; $\mathrm{P}=0.038)$. The initial symptoms included early satiety, chest pain, dysphagia, dyspnea, acid regurgitation, and heartburn. All patients were diagnosed as having hiatal hernia under gastroscopy including 83 cases $(55.3 \%)$ associated with reflux esophagitis and esophageal manometry demonstrated the low esophageal sphincter pressure (LESP) in the elderly group was $6.70 \pm 1.92 \mathrm{mmHg}$ on average as compared to the younger group $6.95 \pm 1.78 ; \mathrm{P}=0.423$.

\section{Perioperative outcome (Table 2)}

All patients underwent successful laparoscopic hiatal hernia repair with mesh reinforcement and no cases were converted to open surgery. Surgeon recorded the percentage of herniated stomach during operation and there was similar blood loss, operating time, and average proportion of herniated stomach between the two groups without blood transfusion. The hernia contained $>50 \%$ of the stomach in $50.0 \%$ of patients in the elderly group as compared to $35 \%$ in the younger group $(\mathrm{P}=0.102)$. Six cases $(9.7 \%)$ in the elderly group and two cases $(3.2 \%)$ in the younger group were transferred to the Intensive Care Unit after operation for tracheal intubation support and then returned to the general ward safely after being stabilized. In the elderly group, 4 patients $(8.1 \%)$ encountered pneumonia and 1 patient $(1.2 \%)$ encountered atelectasis after the operation but quickly recovered after medical treatment. The length of postoperative hospital stay was significantly shorter in the younger group than the elderly group (2.4 vs. 3.5; $\mathrm{P}=0.001)$.

\section{Follow up outcome (Tables 3,4)}

The follow up index included a comparison of postoperative symptoms, hemoglobin, pulmonary function (FEV1\%), application of anti-acid medicine, and upper GI series. All patients were followed up by a combination of telephone interview and outpatient clinic visit at $6 \mathrm{~ms}$ after operation and patients in both groups reported their symptoms were significantly improved $(\mathrm{P}=0.001)$. Pulmonary function (FEV1\%) improved significantly from $83.0 \pm 7.0$ to $91.3 \pm 5.9(\mathrm{P}=0.001)$ in the elderly group as compared with the younger group from $86.4 \pm 6.8$ to $92.8 \pm 4.3(\mathrm{P}=0.001)$, and the percentage of patients who needed to take PPI decreased from $66.1 \%$ before surgery to $6.2 \%$ in the late post-operative period $(\mathrm{P}=0.001)$, which was similar to the 
Table 1 Perioperative evaluation outcome

\begin{tabular}{|c|c|c|c|}
\hline Characteristic & Elderly group $(\geq 75)(\mathrm{N}=62)$ & Younger group $(<75)(\mathrm{N}=88)$ & $P$ value \\
\hline$\%$ Female & 69.4 & 45.5 & \\
\hline Associated with cardiovascular and cerebrovascular diseases (\%) & $39(64.5)$ & $31(35.2)$ & 0.001 \\
\hline Hypertension & $24(38.7)$ & $25(28.4)$ & 0.185 \\
\hline Coronary heart disease & $16(25.8)$ & $6(6.8)$ & 0.001 \\
\hline Cerebral infraction & $9(14.5)$ & $6(6.8)$ & 0.122 \\
\hline Initial symptoms (\%) & & & 0.902 \\
\hline Early satiety & $15(24.2)$ & $25(28.4)$ & \\
\hline Dyspnea & $6(9.7)$ & $10(16.1)$ & \\
\hline Acid regurgitation & $5(8.1)$ & $8(9.1)$ & \\
\hline Heartburn & $6(9.7)$ & $7(8.5)$ & \\
\hline Others & $4(6.5)$ & $4(4.5)$ & \\
\hline ASA Class (\%) & & & 0.038 \\
\hline 1 or 2 & $51(82.3)$ & $82(93.2)$ & \\
\hline 3 & $11(17.7)$ & $6(6.8)$ & \\
\hline \multicolumn{4}{|l|}{ Gastroscopy (\%) } \\
\hline
\end{tabular}

ASA, American Society of Anesthesiology; LESP, lower esophageal sphincter pressure.

younger group. The hemoglobin improved significantly from $105.5 \pm 2.6$ to $113.0 \pm 12.7(\mathrm{P}=0.001)$ in the elderly group as compared with the younger group from $110.6 \pm 17.3$ to $119.4 \pm 12.6(\mathrm{P}=0.001)$. No clinical recurrence was detected during follow up in either group.

\section{Comparison of GIQLI scores (Table 5)}

A significant improvement in GIQLI scores as a measure of patient satisfaction was demonstrated in the two groups and there was no significant difference in either the preoperative or postoperative QOLRAD scores between the elderly and younger groups.

\section{Discussion}

Giant hiatal hernia accounts for $0.3 \%$ to $15 \%$ of all $\mathrm{HH}$ and has a higher surgical recurrence rate $(10.1 \%)(2,18)$. Over the last few decades, a laparoscopic approach involving complete separation of the hernial sac from the thoracic cavity (19) has gradually replaced open repair of giant hiatal hernia to become the standard approach, resulting in lower mortality and better life quality (GIQLI) $(4,14,15)$. Routine fundoplication is also recommended for giant hiatal hernia patients $(20,21)$. Laparoscopic surgery has proven sustained benefits in improving symptoms and quality of life in patients with symptomatic hiatal hernia. The possible postoperative complications include dysphagia, gas 
Table 2 Perioperative outcome

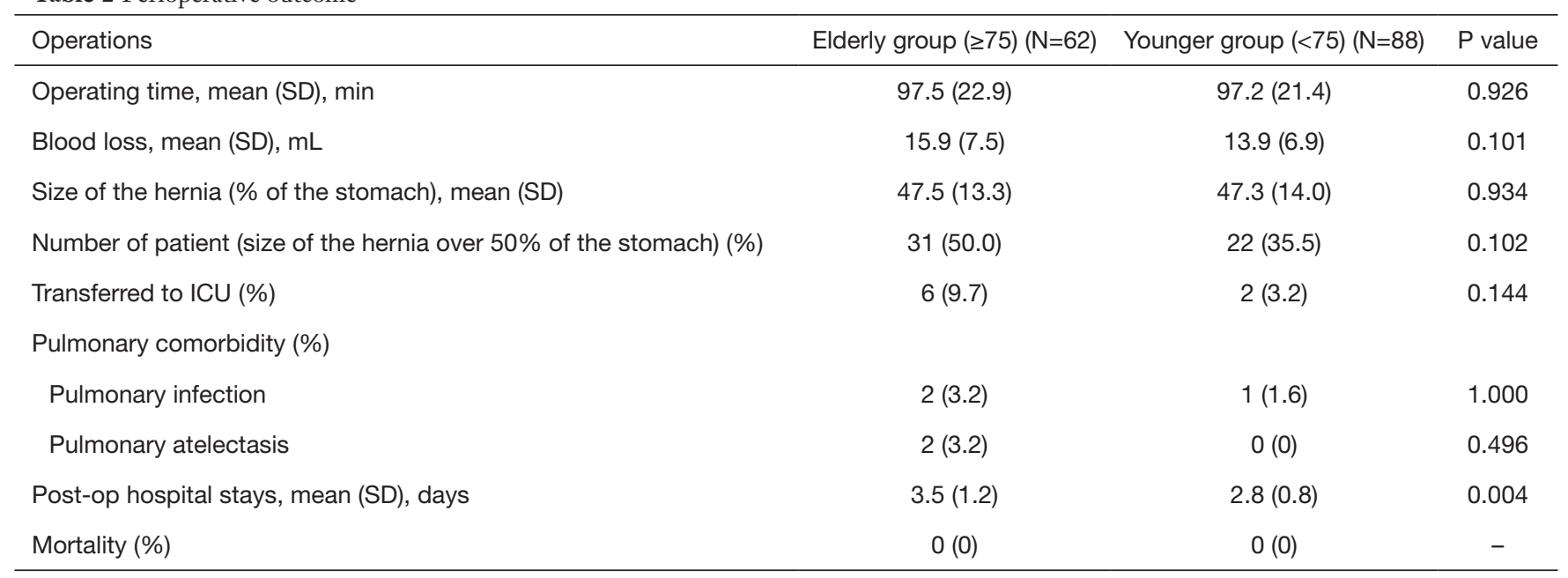

ICU, intensive care unit.

Table 3 Comparison of preoperative and follow up outcomes for the elderly group

\begin{tabular}{|c|c|c|c|}
\hline Symptoms & Pre-op & Post-op & $P$ value \\
\hline Early satiety & $5.6(1.8)$ & $1.6(0.6)$ & 0.001 \\
\hline Chest pain & $6.0(1.6)$ & $1.9(1.1)$ & 0.001 \\
\hline Dysphagia & $5.8(1.5)$ & $1.0(0.6)$ & 0.001 \\
\hline Acid regurgitation & $5.1(1.5)$ & $1.7(0.6)$ & 0.001 \\
\hline Heartburn & $5.4(1.5)$ & $1.8(0.7)$ & 0.001 \\
\hline Hemoglobin & $105.5(20.6)$ & $113.0(12.7)$ & 0.018 \\
\hline Pulmonary function (FEV1\%) & $83.0(7.0)$ & $91.3(5.0)$ & 0.001 \\
\hline
\end{tabular}

FEV1, forced expiratory volume in the first second; PPI, proton pump inhibitor.

bloating, diarrhea. These complications normally recover less than $3 \mathrm{~ms}$ after diet instruction. Tailored surgery (partial or total fundoplication) is the key step for the satisfactory outcome after surgery. The factors might affect the longterm prognosis are abdominal pressure and body weight. The obesity and high abdominal pressure are risk factors for recurrence.

A series of studies have reported acute complications of giant hiatal hernia such as acute gastric volvulus, intrathoracic gastric perforation, and incarcerated obstruction of the herniated viscera $(8,13,22,23)$. Romano et al. demonstrated the length of stay and mortality of elderly patients was obviously increased in a non-elective giant hiatal hernia repair group compared with an elective repair group (24). Therefore, timely surgical treatment is very important for patients with giant hiatal hernia.

The prevalence of elderly patients with giant hiatal hernia continues to rise with increasing life expectancy in an ageing population (11). Some studies consider elderly patients undergoing giant hiatal hernia surgery to be at higher risk of complications and mortality because of their advanced age and comorbidities $(25,26)$. Gangopadhyay reported that an older patient group ( $\geq 75$ years) undergoing laparoscopic paraesophageal hernia repair were associated 
Table 4 Comparison of preoperative and follow up outcomes for the younger group

\begin{tabular}{|c|c|c|c|}
\hline Symptoms & Pre-op & Post-op & $P$ value \\
\hline Early satiety & $5.8(1.7)$ & $1.8(0.7)$ & 0.001 \\
\hline Chest pain & $6.5(1.3)$ & $2.0(0.6)$ & 0.001 \\
\hline Dysphagia & $5.6(1.9)$ & $1.7(0.7)$ & 0.001 \\
\hline Acid regurgitation & $4.7(1.9)$ & $1.5(0.8)$ & 0.001 \\
\hline Heartburn & $4.8(1.9)$ & $1.5(0.6)$ & 0.001 \\
\hline Hemoglobin & $110.6(17.3)$ & $119.4(12.6)$ & 0.001 \\
\hline Pulmonary function (FEV1\%), mean (SD) & $86.4(6.8)$ & $92.8(4.3)$ & 0.001 \\
\hline
\end{tabular}

FEV1, forced expiratory volume in the first second; PPI, proton pump inhibitor.

Table 5 Comparison of GIQLI scores

\begin{tabular}{|c|c|c|c|}
\hline Grade, mean (SD) & Elderly group $(\geq 75)(\mathrm{N}=62)$ & Younger group $(<75)(\mathrm{N}=88)$ & $P$ value \\
\hline Post-op GIQLI, mean (SD) & $108.5(5.8)$ & $109.3(5.8)$ & 0.424 \\
\hline Interval improvement in GIQLI scores & $21.0(6.6)$ & $22.5(7.4)$ & 0.176 \\
\hline Pre-op post post-op GIQLI P value & 0.001 & 0.001 & - \\
\hline
\end{tabular}

GIQL, gastrointestinal quality of life index.

with more complications than other groups (65-74 years group and $<65$ years group) (27). On the other hand, Khoma et al. demonstrated good outcomes for laparoscopic giant hiatal hernia repair and Nissen fundoplication in a group of 89 patients over 80 years old (10).

Our results suggest giant hiatal hernia is relatively safe for elderly patients in comparison to younger patients. Although $64.5 \%$ of patients in our study had concomitant cardiovascular and cerebrovascular diseases, most recovered uneventfully from the procedure. The 30-day mortality $(0 \%)$ was similar to the younger group and that reported in other studies (15). Elderly patients also had a higher percentage of intrathoracic stomach consistent with younger patients without increasing operative complications. However, elderly patients also trended towards a higher rate of transfer to the intensive care unit after operation (9.6\% vs. $3.2 \%)$, and ICU departments need to be prepared for this. Surgical outcomes for elderly patients were also favorable in this cohort compared to the younger group. Significant improvement in early satiety, chest pain, dysphagia, dyspnea, acid regurgitation, heartburn, and life quality were sustained during follow up, and this was similar to the younger group and the results of the study by Khoma (10). Of course, various precaution needs to be taken for elderly patients, for instance thorough preoperative evaluation, and less operating time, lower pneumoperitoneum pressure and ICU care when necessary.

During follow up, there was no anatomic recurrence case in either group. The essential steps to avoid anatomical recurrence include fully dissection of abdominal esophagus, complete resection of hernia sac, proper closure of hiatus and reinforcement with mesh. While previous research reported fundoplication and mesh-related complications such as intraluminal erosion, fibrosis, and esophageal stenosis $(2,27)$, there was no mesh related complications in our research. Patients with giant hiatal hernia often complain of symptoms including early satiety, chest pain, dysphagia, and dyspnea. These symptoms result from the compression of lung volume, insufficiency of resultant ventilation, and perfusion mismatch (28). In our study, 
pulmonary function (FEV1\%) raised from $105.5 \pm 20.6$ to $113.0 \pm 12.7$ and all related symptoms were recovered after the complete reduction of herniated stomach in elderly group. Previous research has also indicated improvement in respiratory function after the procedure $(28,29)$.

In conclusion, our retrospective study showed laparoscopic giant hiatal hernia repair for elderly patients was performed with low morbidity and a significant improvement in QOLRAD scores after operation demonstrating considerable benefit. Thorough preparation and anesthesia evaluation are essential for the safety of the procedure and its benefits and risks need to be carefully evaluated. Ideally, a prospective multiple- centre study with large number of cases to further confirm the outcome.

\section{Acknowledgments}

Funding: This work was supported by the Capital Foundation of Medical Development (No. 2020-2-2035 to $\mathrm{HY})$.

\section{Footnote}

Reporting Checklist: The authors have completed the STROBE reporting checklist. Available at http://dx.doi. org/10.21037/atm-21-1495

Data Sharing Statement: Available at http://dx.doi. org/10.21037/atm-21-1495

Conflicts of Interest: All authors have completed the ICMJE uniform disclosure form (available at http://dx.doi. org/10.21037/atm-21-1495). The authors have no conflicts of interest to declare.

Ethical Statement: The authors are accountable for all aspects of the work in ensuring that questions related to the accuracy or integrity of any part of the work are appropriately investigated and resolved. All procedures performed in this study involving human participants were in accordance with the Declaration of Helsinki (as revised in 2013). The study was approved by institutional ethics committee of Beijing Chaoyang Hospital (No.: 2020-22035). Individual consent for this retrospective analysis was waived.

Open Access Statement: This is an Open Access article distributed in accordance with the Creative Commons
Attribution-NonCommercial-NoDerivs 4.0 International License (CC BY-NC-ND 4.0), which permits the noncommercial replication and distribution of the article with the strict proviso that no changes or edits are made and the original work is properly cited (including links to both the formal publication through the relevant DOI and the license). See: https://creativecommons.org/licenses/by-nc-nd/4.0/.

\section{References}

1. Kohn GP, Price RR, Demeester SR, et al. Guidelines for the management of hiatal hernia. Surg Endosc 2013;27:4409-28.

2. Karamanolis G, Polymeros D, Triantafyllou K, et al. Hiatal hernia predisposes to nocturnal gastro-oesophageal reflux. United European Gastroenterol J 2013;1:169-74.

3. Mitiek MO, Andrade RS. Giant hiatal hernia. Ann Thorac Surg 2010;89:S2168-S2173.

4. Fullum TM, Oyetunji TA, Gezzer O, et al. Open versus laparoscopic hiatal hernia repair. JSLS 2013;17:23-9.

5. Chowbey PK, Mittal T, Dey A, et al. Laparoscopic management of large hiatus hernia with mesh cruroplasty. Indian J Surg 2008;70:296-302.

6. Chang CG, Thackeray L. Laparoscopic hiatal hernia repair in 221 patients: outcomes and experience. JSLS 2016;20:e2015.00104.

7. Migaczewski M, Grzesiak-Kuik A, Pędziwiatr M, et al. Laparoscopic treatment of type III and IV hiatal hernia authors' experience. Wideochir Inne Tech Maloinwazyjne 2014;9:157-63.

8. Priego P, Ruiz-Tovar J, Pérez de Oteyza J. Long-term results of giant hiatal hernia mesh repair and antireflux laparoscopic surgery for gastroesophageal reflux disease. J Laparoendosc Adv Surg Tech A 2012;22:139-41.

9. Evans DB. Health systems financing and the path to universal coverage. Bull World Health Organ2010;88:402.

10. Khoma $\mathrm{O}$, Mugino $M$, Falk GL. Is repairing giant hiatal hernia in patients over 80 worth the risk? Surgeon 2020;18:197-201.

11. Parker DM, Rambhajan AA, Horsley RD, et al. Laparoscopic paraesophageal hernia repair is safe in elderly patients. Surg Endosc 2017;31:1186-91.

12. Tolone S, Docimo G, Del GG, et al. Long term quality of life after laparoscopic antireflux surgery for the elderly. BMC Surg 2013;13:S10.

13. Grotenhuis BA, Wijnhoven BPL, Bessell JR, et al. Laparoscopic antireflux surgery in the elderly. Surg Endosc 2008;22:1807-12. 
14. Hazebroek EJ, Gananadha S, Koak Y, et al. Laparoscopic paraesophageal hernia repair: quality of life outcomes in the elderly. Dis Esophagus 2008;21:737-41.

15. Oor JE, Koetje JH, Roks DJ, et al. Laparoscopic Hiatal Hernia Repair in the Elderly Patient. World J Surg 2016;40:1404-11.

16. David IW. Current state of repair of large hiatal hernia. International Journal of Abdominal Wall and Hernia Surgery 2019;2:39-43.

17. Luketich JD, Nason KS, Christie NA, et al. Outcomes after a decade of laparoscopic giant paraesophageal hernia repair. J Thorac Cardiovasc Surg 2010;139:395-404.

18. Blum MG, Sundaresan RS. Giant hiatal hernia with Gastric Volvulus Complicating Pneumonectomy. Ann Thorac Surg 2006;81:1491-2.

19. Lococo F, Cesario A, Meacci E, et al. Intrathoracic gastric perforation: a late complication of an unknown postpartum recurrent hiatal hernia. Interact Cardiovasc Thorac Surg 2012;15:317-8.

20. Ponte A, Pinho R, Viveiros F, et al. Incarcerated giant hiatal hernia. Endoscopy 2014;46 Suppl 1 UCTN:E561-2.

21. Poulose BK, Gosen C, Marks JM, et al. Inpatient mortality analysis of paraesophageal hernia repair in octogenarians. J Gastrointest Surg 2008;12:1888-92.

22. Lesinski J, Zielonka TM, Wajtryt O, et al. Giant hiatal hernias. Adv Respir Med 2019;87:54-62.

Cite this article as: Guan L, Nie Y, Yuan X, Chen J, Yang H. Laparoscopic repair of giant hiatal hernia for elderly patients. Ann Transl Med 2021;9(8):704. doi: 10.21037/atm-21-1495
23. Ozawa H, Shinozaki H, Kimata M, et al. Case of giant paraesophageal hiatal hernia associated with Morgagni hernia. Asian J Endosc Surg 2018;11:43-6.

24. Romano A, D'Amore D, Esposito G, et al. Characteristics and outcomes of laparoscopic surgery in patients with large hiatal hernia. A single center study. Int J Surg Case Rep 2018;48:142-4.

25. Li ZT, Ji F, Han XW, et al. Role of fundoplication in treatment of patients with symptoms of hiatal hernia. Sci Rep 2019;9:12544.

26. Furnée EJB, Draaisma WA, Gooszen HG, et al. Tailored or Routine Addition of an Antireflux Fundoplication in Laparoscopic Large Hiatal Hernia Repair: A Comparative Cohort Study. World J Surg 2011;35:78.

27. Gangopadhyay N, Perrone JM, Soper NJ, et al. Outcomes of laparoscopic paraesophageal hernia repair in elderly and high-risk patients. Surgery 2006;140:491-8; discussion 498-9.

28. Zhu JC, Becerril G, Marasovic K, et al. Laparoscopic repair of large hiatal hernia: impact on dyspnoea. Surg Endosc 2011;25:3620-6.

29. Naoum C, Falk GL, Ng AC, et al. Left Atrial Compression and the Mechanism of Exercise Impairment in Patients With a Large Hiatal Hernia. J Am Coll Cardiol 2011;58:1624-34.

(English Language Editor: B. Draper) 